\title{
Reports
}

\section{Obesity in the geriatric population - a global health perspective}

\author{
Jason H Malenfant ${ }^{1}$, John A Batsis ${ }^{1}$ \\ ${ }^{1}$ Section of General Internal Medicine, Dartmouth-Hitchcock Medical Center, Lebanon, New Hampshire \\ Keywords: global health \\ https://doi.org/10.29392/joghr.3.e2019045
}

Journal of Global Health Reports

Vol. 3, 2019

\begin{abstract}
The obesity crisis has been a major concern for public health organizations worldwide, and affects the geriatric population in parallel to that of the general population. Though geriatric obesity has been recognized in developed countries, such trends have also extended into developing countries due to disproportionate consumption of energy-dense low-cost food and increasingly sedentary lifestyles. The consequences of geriatric obesity include impaired physical function, decreased quality of life, institutionalization and death. The aim is to describe the obesity epidemic in both developed and developing countries, as well as highlight current surveillance efforts to monitor geriatric obesity on a global scale such as the Study on Global Ageing and Adult Health (SAGE study), which evaluates epidemiology trends in six different countries (China, Ghana, India, Mexico, Russia and South Africa). The impact of obesity on health, disease and systems worldwide will be described, as well as projections of future trends of this disease.
\end{abstract}

The global obesity crisis has been a major concern for public health organizations worldwide. The prevalence of obesity in the older population has been on the rise, and now poses a major global threat in both developed and developing countries. Overall age-adjusted prevalence of obesity in the United States is estimated to be $35.0 \%$ among men and $40.4 \%$ among women. ${ }^{1}$ These rates parallel those observed in the geriatric population, with $37.1 \%$ of men and $33.6 \%$ of women aged 60 years and older classified as having obesity (based on a body mass index $(\mathrm{BMI}) \geqslant 30 \mathrm{~kg} / \mathrm{min}^{2}$ ). In this same age range, the rates of being classified as overweight are $78.4 \%$ for men and $68.6 \%$ for women. ${ }^{2}$ Recently, a systematic analysis for the Global Burden of Disease Study revealed a worldwide increase in the prevalence of overweight and obesity by $27.5 \%$ between 1980 and 2013. This task force examined all major multi-country survey programs that included information on height and weight of their citizens, gathering statistics from 188 countries ranging from the most developed to least developed. ${ }^{3}$ Though this issue has for some time been recognized as a large public health concern in the Western World, it is becoming increasingly clear that this now represents a major global public health issue as it has extended into developing countries.

Several major factors have been identified in driving this worsening pandemic. Worldwide, there has been a general increase in the intake of energy-dense foods ${ }^{4}$ and 'westernization' of countries that were previously less developed. Increasing sedentary forms of work, expanding urbanization, and changes in mode of transportation have prompted an overall decrease in levels of physical activity. ${ }^{4}$ As solutions and new initiatives for this worsening global dilemma are being sought in health promotion and disease prevention, it is important to first understand the current climate in this field: the initiatives underway, the impact these may have (if any), and any current limitations in the approach to solving this major issue.

\section{DEVELOPED VS. DEVELOPING COUNTRIES}

In developed countries such as the United States, the obesity crisis is largely driven by disproportionately high calorie diets and increasingly sedentary lifestyles. ${ }^{5}$ Though a newer phenomenon, this is now being observed in developing nations as well. In these countries, there has been a significant rise in the consumption of energy-dense but micronutrient-poor foods given that they are lowest in cost. ${ }^{4}$ In addition, reductions in energy expenditure activities such as farming and forestry along with a concomitant increase in sedentary leisure activities such as sitting at a computer or television have been identified. ${ }^{6,7}$ In African nations between the years 1981-1990, a surge in obesity rates was observed. This was due in part to a substantial reduction in physical activity due to road development and taxis and buses becoming the most common means of transportation, as well as a shift away from manual labor jobs. The obesity rates are beginning to approach those of developed countries. ${ }^{8}$ There is also likely a component of reduced education and resources contributing to these recent trends and rising concerns. An inverse relationship has been observed between education level and the risk of developing multimorbidity. ${ }^{9-11}$ In fact, education is reported to be the socioeconomic indicator that most significantly predicts diet quality. ${ }^{12}$ Much is thought to be contributed by the lack of health literacy and poor knowledge of proper dietary choices and food purchasing behavior. ${ }^{13}$ Future projections suggest a much larger proportional increase in the number of overweight and obese individuals by 2030 in developing nations compared to developed regions as a result of these changes in sociodemographic characteristics. ${ }^{14}$ 
There remains a need for more evidence to differentiate risk factors in the elderly versus the younger adult population for obesity, particularly in developing countries. However, these general trends observed can likely be inferred to impact both these populations.

\section{THE IMPORTANCE OF GERIATRIC OBESITY}

\section{CONSEQUENCES OF OBESITY IN THE ELDERLY}

Obesity, in general, increases the risk of developing coronary heart disease, ${ }^{15}$ hypertension, ${ }^{16}$ diabetes, ${ }^{17}$ and obstructive sleep apnea, ${ }^{18}$ and has been linked to certain cancers ${ }^{4}$ reduced life expectancy, ${ }^{19}$ and increased risk of premature mortality. ${ }^{20}$ While such co-morbidity is important in the elderly, quality of life and functional status often become of more significant interest to such patients. Obesity itself is associated with greater limitations in activities of daily living and a larger increase in functional impairments. ${ }^{21}$

Chen and Guo $(2008)^{21}$ used data from NHANES 1999-2004 and evaluated older adults' functional status aged $\geqslant 60$ years. Each subject rated their level of difficulty (on a 4 point scale) with performing a number of tasks, including locomotion and transfers, household productivity and manipulation of their surroundings. These were grouped into five major categories: activities of daily living, instrumental activities of daily living, leisure and social activities, lower extremity mobility, and general physical activities. ${ }^{22}$ The authors found that both BMI and waist circumference were positively associated with all measures of functional disabilities in women. ${ }^{21}$ Compared with the lowest quartile of waist circumference $(<87.0 \mathrm{~cm})$, odds ratios and 95\% confidence intervals (CI) of the highest quartile $(>104.2 \mathrm{~cm})$ for having difficulties in functional domains were 2.4 (95\% CI=1.6-3.6) for activities of daily living, 2.3 (95\% CI=1.6-3.3) for instrumental activities of daily living, 2.6 (95\% CI=1.6-4.1) for leisure and social activities, 4.8 (3.4-6.9) for lower extremity mobility and 2.9 (95\% $\mathrm{CI}=2.1-4.0$ ) for general physical activities. In men, they were similarly associated with most measures of disabilities, but less so for activities of daily living and instrumental activities of daily living. ${ }^{21}$

Other studies have produced similar findings. Al Snih et al. ${ }^{23}$ investigated data from five sites of the Established Populations for Epidemiologic Studies of the Elderly, following a total of 12,725 Americans who were not disabled at baseline (8359 non-Hispanic white Americans, 1931 African Americans and 2435 Mexican Americans) over a 7 year span. Their findings concluded that a disability-free life expectancy was greatest in subjects with BMI of $25-30 \mathrm{~kg} / \mathrm{m} 2$, and those $>30 \mathrm{~kg} / \mathrm{m} 2$ at baseline were significantly more likely to experience disability. ${ }^{23}$ A systematic review of 13 cross-sectional and 15 longitudinal studies on this subject also reported that a BMI of $30-35 \mathrm{~kg} / \mathrm{m} 2$ is the point when mobility limitations are more likely to develop. ${ }^{24}$ A metaanalysis of 26 studies by Schaap et al. ${ }^{25}$ similarly revealed a direct correlation between obesity and functional decline, usually self-reported, in comparison to normal weight. Of note, they found this to be true looking at all the different measures of obesity, such as BMI, waist circumference and higher body fat percentage.

Patients with obesity are also more likely to require hospitalization and more likely to require surgery. In the U.S., four of the five most common reasons for hospital admissions in the elderly are congestive heart failure, coronary atherosclerosis, cardiac dysrhythmias and acute myocardial infarctions, all which have associations with obesity. ${ }^{26} \mathrm{~A}$ disproportionate amount of invasive surgical procedures that have ties to obesity are also performed in this subgroup, with over $70 \%$ of all cardiothoracic surgeries and nearly $60 \%$ of all general surgery cases being performed in adults over 65 years. ${ }^{27}$ Hospitalizations in an older population leads to further impaired outcomes of functional decline, delirium, institutionalization and death. In synergy with obesity, this amounts to an increase in healthcare utilization and adverse events.

One emerging concept is that of normal weight obesity. These are subjects with a normal BMI but elevated waistto-hip ratio or waist circumference. A recently published study sought to examine the mortality risk in older adults with coronary artery disease (CAD) who were classified as having normal-weight central obesity. A total of 7,057 patients aged 65 years or older (mean age $73.0+/-6.0$ years) were identified from five cohort studies and grouped into categories by whether they had normal, overweight or obese BMI $18.5-24.9 \mathrm{~kg} / \mathrm{m}^{2}, 25-29.9 \mathrm{~kg} / \mathrm{m}^{2}$, and $\geqslant 30 \mathrm{~kg} / \mathrm{m}^{2}$, respectively), and if they had high or low waist circumference (high defined as $\geqslant 88 \mathrm{~cm}$ for women and $\geqslant 102 \mathrm{~cm}$ for men) or high or low waist-hip ratio (high defined as $\geqslant 0.85$ for women and $\geqslant 0.90$ for men). The authors found the highest mortality risk to actually be in the normal BMI and central obesity cohorts (either high waist circumference or high waist-hip ratio), reporting hazard ratios (HR) of 1.29 (95\% $\mathrm{CI}=1.13-1.46)$ in the high waist circumference group and 1.29 (95\% CI=1.12-1.50) in the high waist-hip ratio group. ${ }^{28}$ Importantly, subjects with normal weight obesity have higher cardiometabolic disorders and can inadvertently be ignored in clinical practice.

\section{IS IT SAFE TO ADVISE OLDER ADULTS TO LOSE WEIGHT?}

The subject of weight loss interventions in older adults remains a controversial topic. First, there are studies that have demonstrated that increased adiposity may have a "protective" effect in older adults (the "obesity paradox"). Some studies have shown that being overweight has been associated with the lowest mortality compared to all other BMI ranges, and this is most pronounced in older adults. ${ }^{29,30}$ This concept often relates to chronic diseases of inflammation including end-stage renal disease and chronic heart failure. Each of these diseases are often characterized by sarcopenia, the loss of muscle mass and function with aging. ${ }^{31}$ Another hypothesis stems from the impact of cardiorespiratory fitness in adults with obesity portending to better outcomes. Although the presence of obesity increases the risk of developing these chronic conditions, once present, patients with obesity tend to have higher survival rates. ${ }^{32}$ Some speculate this is due, in part, to the presence of larger stores of body mass (and therefore energy) as well as a better overall nutritional status. ${ }^{33}$ 
Lastly, in contrast to earlier published epidemiologic studies, it is important to identify studies evaluating intentional weight loss in this population, as unintentional weight loss is often the harbinger of frailty and death. Larger population-based cohort studies out of the U.K. and the U.S. ${ }^{34,35}$ have shown that unintentional weight loss is a poor predictor of mortality. Surprisingly, the Melbourne Longitudinal Studies on Healthy Ageing (MELSHA), which enrolled 1,000 participants, found a protective effect of unintentional weight loss. However, these findings were most attributable to those who had already started with significant excess body weight, ${ }^{36}$ which emphasizes the complexity of this topic and gives clear reason for why this is often a more patient-specific approach.

\section{OBESITY PARADOX IN DEVELOPED COUNTRIES}

One systematic review and meta-analysis examined the association of all-cause mortality with overweight and obesity as defined by BMI. Prospective studies in the general population were evaluated that reported hazard ratios (HR) for all-cause mortality for overweight $(0.94$ [95\% CI, 0.91-0.96]), grade 1 obesity (HR 0.95 [0.88-1.01]), and grades 2 and 3 obesity (HR 1.29 [1.18-1.41]) relative to normal weight. All grades of obesity combined had a HR 1.18 [1.12-1.25]. These results suggested an inflection point where mortality starts increasing. The most striking finding was that compared to normal BMI, being overweight was associated with significantly lower all-cause mortality, most evident in older adults. ${ }^{29}$ Unfortunately, there is little data evaluating these constructs in developing countries forcing researchers to extrapolate data from developed countries.

\section{GLOBAL SURVEILLANCE OF GERIATRIC OBESITY}

The World Health Organization (WHO) oversees the Study on Global Ageing and Adult Health (also referred to as the SAGE survey) that monitors health in older adults. This survey was derived to observe the process of aging and its health effects, and compare aging populations in various countries across the globe. This longitudinal study cohort follows adults 50 years and over in six different countries (China, Ghana, India, Mexico, Russia and South Africa) and provides a comparison to a smaller cohort aged 18 to 49 in those countries. Baseline data was obtained between 2002-2004, and the first wave of new data was extracted between 2007-2010. The second wave of data collection was finished in 2015 and the third and final data wave will be completed in 2017. ${ }^{37}$ Variations and comparisons between these countries can be performed to evaluate global trends.

Data from wave 1 indicates that the degree of obesity and other major health risk factors varied significantly by country, but there was a clear trend that the rate of non-communicable disease overall has increased globally, and will continue to increase. ${ }^{38}$

The SAGE study also examines six "major" health risk factors: physical inactivity, tobacco use, heavy alcohol consumption, a high-risk waist to hip ratio, hypertension and obesity. This data revealed that the percentage of citizens with at least three of these six risk factors tended to increase with age, although the proportions vary by coun- try. ${ }^{38}$ With the release of the SAGE wave 1 results, further analysis has been performed to look at variations by country. A study examining the results in South Africa revealed that women were at a much greater risk of developing central obesity compared to men when aged 50 or older $(33 \%$ of women vs $20 \%$ of men). This was true when central obesity was measured both as waist circumference and waist to hip ratio. Examining these trends also showed that in this country, older men were at higher risk of central obesity if they were higher income, had a postgraduate education and were never married. ${ }^{39}$ Similarly, a recent study reviewing the SAGE data obtained in India showed a higher propensity for central adiposity in women, in those with higher education, from a privileged caste, urban residence and a whitecollared occupation. ${ }^{40}$

\section{LOOKING FORWARD IN THE FUTURE}

\section{COSTS OF OBESITY}

The economic impact of our aging population that is developing obesity will continue to grow. Using a nationally representative data set, approximately $9.1 \%$ of all medical expenditures in the United States in 1998 were attributable to overweight or obesity and about half of this was financed by public funds. ${ }^{41}$ In Canada, an entirely publicly funded system, approximately $2.2 \%$ of all healthcare costs were attributable to obesity in $2001 .{ }^{42}$ It was estimated that $1.2 \%$ of total GDP in the U.S. in 2001 was spent towards obesity-related costs. This issue has been observed in other parts of the globe as well, with India incurring roughly the same annual percentage of GDP cost (according to data reported in 1995), and China reporting nearly double the cost of both those countries in 1995. ${ }^{43}$

Future predictions are concerning. Certain authors have predicted that in the United States alone, based on current trends, total healthcare costs related to obesity could be as high as US\$ 861 to US\$ 957 billion by the year 2030, which would account for $16-18 \%$ of all total U.S. health-care costs. ${ }^{44}$ The United Kingdom (UK) predicts that with their current trend in obesity, there will be a GBP 5.5 billion (US\$ 6.9 billion) increase in medical costs to the National Health Service (NHS) by 2050. ${ }^{45}$

\section{THE FUTURE}

Global projections of the obesity epidemic continue to show upward trends. ${ }^{14,38,44,46}$ It has been suggested that if current patterns continue, there is essentially zero probability of reaching the WHO goal of halting the rise in obesity. ${ }^{46}$ Obesity is a preventable disease, ${ }^{4}$ and while its treatment is outside the scope of this epidemiologic review, more effective health promotion interventions are needed for dissemination. While worldwide recognition and acceptance of this epidemic continues to grow, little emphasis has been given to the older adult population with obesity and there are unique factors and challenges that must be understood in its management. ${ }^{47}$ More specific data in this area related to this population would provide the breadth for effective policy implementation and change. With a growing aging demographic, special attention needs to be paid to this group of patients whose life expectancy continues to increase, and 
trends in disability rates continue to rise. ${ }^{48}$ Striving for a healthier lifestyle can compress incident disability, ${ }^{49}$ leading to a healthier society and a more cost-effective health care system.

\section{ACKNOWLEDGEMENTS}

We thank Avantika Tankala for her editorial assistance.

\section{DISCLAIMER}

The findings and conclusions in this journal article are those of the authors and do not necessarily represent the official position of the Centers for Disease Control and Prevention.

\section{FUNDING}

Dr. Batsis' research reported in this publication was supported in part by the National Institute on Aging of the National Institutes of Health under Award Number K23AG051681. The content is solely the responsibility of the authors and does not necessarily represent the official views of the National Institutes of Health. Support was also provided by the Dartmouth Health Promotion and Disease Prevention Research Center supported by Cooperative Agreement Number U48DP005018 from the Centers for Disease Control and Prevention.

\section{COMPETING INTERESTS}

The authors have completed the Unified Competing Interest form at http://www.icmje.org/coi disclosure.pdf (available on request from the corresponding author) and declare no conflict of interest.

\section{CORRESPONDENCE TO:}

John A. Batsis, MD, FACP, AGSF

Section of General Internal Medicine

Dartmouth-Hitchcock Medical Center

1 Medical Center Drive

Lebanon, NH 03756 USA

john.batsis@gmail.com 


\section{REFERENCES}

1. Flegal KM, Kruszon-Moran D, Carroll MD, Fryar CD, Ogden CL. Trends in obesity among adults in the United States, 2005 to 2014. JAMA.

2016;315(21):2284-2291. doi:10.1001/jama.2016.6458

2. Flegal KM, Carroll MD, Kit BK, Ogden CL.

Prevalence of obesity and trends in the distribution of body mass index among US adults, 1999-2010. JAMA. 2012;307(5):491-497. doi:10.1001/jama.2012.39

3. Ng M, Fleming T, Robinson M, et al. Global, regional, and national prevalence of overweight and obesity in children and adults during 1980-2013: a systematic analysis for the Global Burden of Disease Study 2013. Lancet. 2014;384(9945):766-781. doi:10.1 $\underline{016 / \mathrm{s} 0140-6736(14) 60460-8}$

4. World Health Organization. Obesity and overweight fact sheet. Accessed May 12, 2017. http s://www.who.int/news-room/fact-sheets/detail/obesit y-and-overweight

5. Centers for Disease Control and Prevention. Adult obesity causes \& consequences. Accessed May 14, 2017. https://www.cdc.gov/obesity/adult/causes.html

6. Bergier J, Kapka-Skrzypczak L, Bilinski P, Paprzycki P, Wojtyla A. Physical activity of Polish adolescents and young adults according to IPAQ: a population based study. Ann Agric Environ Med. 2012;19:109-115.

7. Popkin B. The nutrition transition and the global shift towards obesity. Diabetes Voice. 2004;49:38-40.

8. Samuel F, Atinmo T. Obesity and cardiovascular diseases: the risk factor in African diets. Forum Public Policy. 2008;1-15.

9. Afshar S, Roderick PJ, Kowal P, Dimitrov BD, Hill AG. Multimorbidity and the inequalities of global ageing: a cross-sectional study of 28 countries using the World Health Surveys. BMC Public Health. 2015;15(1):776. doi:10.1186/s12889-015-2008-7

10. Barnett K, Mercer SW, Norbury M, Watt G, Wyke S, Guthrie B. Epidemiology of multimorbidity and implications for health care, research, and medical education: a cross-sectional study. Lancet. 2012;380(9836):37-43. doi:10.1016/s0140-6736(12)60 $\underline{240-2}$

11. Orueta JF, Nuño-Solinís R, García-Alvarez A, Alonso-Morán E. Prevalence of multimorbidity according to the deprivation level among the elderly in the Basque Country. BMC Public Health. 2013;13(1):918. doi:10.1186/1471-2458-13-918
12. Delavari M, Sønderlund AL, Swinburn B, Mellor D, Renzaho A. Acculturation and obesity among migrant populations in high income countries - a systematic review. BMC Public Health. 2013;13(1):458. doi:10.118 6/1471-2458-13-458

13. Bhurosy T, Jeewon R. Overweight and obesity epidemic in developing countries: a problem with diet, physical activity, or socioeconomic status? Scientific World Journal. 2014;2014:1-7. doi:10.1155/20 $14 / 964236$

14. Kelly T, Yang W, Chen CS, Reynolds K, He J. Global burden of obesity in 2005 and projections to 2030. Int J Obes (Lond). 2008;32(9):1431-1437. doi:10.1038/ijo.2 $\underline{008.102}$

15. Logue J, Murray HM, Welsh P, et al. Obesity is associated with fatal coronary heart disease independently of traditional risk factors and deprivation. Heart. 2011;97(7):564-568. doi:10.1136/h rt.2010.211201

16. Mathieu P, Poirier P, Pibarot P, Lemieux I, Després JP. Visceral obesity: the link among inflammation, hypertension, and cardiovascular disease. Hypertension. 2009;53(4):577-584. doi:10.1161/hypert ensionaha.108.110320

17. Nguyen NT, Nguyen XMT, Lane J, Wang P. Relationship between obesity and diabetes in a US adult population: findings from the National Health and Nutrition Examination Survey, 1999-2006. Obes Surg. 2011;21(3):351-355. doi:10.1007/s11695-010-03 $\underline{35-4}$

18. Lopez PP, Stefan B, Schulman CI, Byers PM. Prevalence of sleep apnea in morbidly obese patients who presented for weight loss surgery evaluation: more evidence for routine screening for obstructive sleep apnea before weight loss surgery. Am Surg. 2008;74:834-888.

19. Fontaine KR, Redden DT, Wang C, Westfall AO, Allison DB. Years of life lost due to obesity. JAMA. 2003;289(2):187-193. doi:10.1001/jama.289.2.187

20. Franks PW, Hanson RL, Knowler WC, Sievers ML, Bennett PH, Looker HC. Childhood obesity, other cardiovascular risk factors, and premature death. $N$ Engl J Med. 2010;362(6):485-493. doi:10.1056/nejmoa $\underline{0904130}$

21. Chen H, Guo X. Obesity and functional disability in elderly Americans. J Am Geriatr Soc. 2008;56(4):689-694. doi:10.1111/j.1532-5415.2007.01 624.X 
22. Kuo HK, Bean JF, Yen CJ, Leveille SG. Linking Creactive protein to late-life disability in the National Health and Nutrition Examination Survey (NHANES) 1999-2002. J Gerontol A Biol Sci Med Sci.

2006;61(4):380-387. doi:10.1093/gerona/61.4.380

23. Al Snih S, Ottenbacher KJ, Markides KS, Kuo YF, Eschbach K, Goodwin JS. The effect of obesity on disability vs mortality in older Americans. Arch Intern Med. 2007;167(8):774-780. doi:10.1001/archinte.16 $\underline{7.8 .774}$

24. Vincent HK, Vincent KR, Lamb KM. Obesity and mobility disability in the older adult. Obes Rev. 2010;11(8):568-579. doi:10.1111/j.1467-789x.2009.00 703.X

25. Schaap LA, Koster A, Visser M. Adiposity, muscle mass, and muscle strength in relation to functional decline in older persons. Epidemiol Rev.

2012;35(1):51-65. doi:10.1093/epirev/mxs006

26. Nagamine M, Jiang HJ, Merrill CT. Trends in elderly hospitalizations, 1997-2004: Statistical Brief \#14. In: Healthcare Cost and Utilization Project (HCUP) Statistical Briefs. Agency for Healthcare Research and Quality; 2006.

27. Etzioni DA, Liu JH, Maggard MA, Ko CY. The aging population and its impact on the surgery workforce. Ann Surg. 2003;238(2):170-177. doi:10.1097/01.sla.00 $\underline{00081085.98792 .3 d}$

28. Sharma S, Batsis JA, Coutinho T, et al. Normalweight central obesity and mortality risk in older adults with coronary artery disease. Mayo Clin Proc. 2016;91(3):343-351. doi:10.1016/j.mayocp.2015.12.00 

29. Flegal KM, Kit BK, Orpana H, Graubard BI. Association of all-cause mortality with overweight and obesity using standard body mass index categories: a systematic review and meta-analysis. JAMA. 2013;309(1):71-82. doi:10.1001/jama.2012.113 $\underline{905}$

30. Allison DB, Gallagher D, Heo M, Pi-Sunyer FX, Heymsfield SB. Body mass index and all-cause mortality among people age 70 and over: the Longitudinal Study of Aging. Int J Obes Relat Metab Disord. 1997;21(6):424-431. doi:10.1038/sj.ijo.080042 $\underline{3}$

31. Kalantar-Zadeh K, Streja E, Kovesdy CP, et al. The obesity paradox and mortality associated with surrogates of body size and muscle mass in patients receiving hemodialysis. Mayo Clin Proc. 2010;85(11):991-1001. doi:10.4065/mcp.2010.0336
32. Brown RE, Kuk JL. Consequences of obesity and weight loss: a devil's advocate position. Obes Rev. 2014;16(1):77-87. doi:10.1111/obr.12232

33. Porter Starr K, McDonald S, Weidner J, Bales C. Challenges in the management of geriatric obesity in high risk populations. Nutrients. 2016;8(5):262. doi:1 0.3390/nu8050262

34. Wannamethee SG, Shaper AG, Lennon L. Reasons for intentional weight loss, unintentional weight loss, and mortality in older men. Arch Intern Med.

2005;165(9):1035-1040. doi:10.1001/archinte.165.9.1 $\underline{035}$

35. Gregg EW, Gerzoff RB, Thompson TJ, Williamson DF. Intentional weight loss and death in overweight and obese U.S. adults 35 years of age and older. Ann Intern Med. 2003;138(5):383-389. doi:10.7326/0003-4 819-138-5-200303040-00007

36. Atlantis E, Browning C, Kendig H. Body mass index and unintentional weight change associated with all-cause mortality in older Australians: the Melbourne Longitudinal Studies on Healthy Ageing (MELSHA). Age Ageing. 2010;39(5):559-565. doi:10.10 93/ageing/afa073

37. World Health Organization. SAGE Waves 0, 1, $2,3$. Accessed June 12, 2017. http://www.who.int/healthinf o/sage/cohorts/en/

38. World Health Organization. Global Health and Aging. WHO; 2011. Accessed June 12, 2017. https://w ww.who.int/ageing/publications/global_health.pdf

39. World Health Organization. Human Science Research Panel (2012) South Africa Study on global AGEing and adult health (SAGE), Wave 1. Accessed June 13, 2017. http://apps.who.int/healthinfo/system s/surveydata/index.php/catalog/5

40. Samal S, Panigrahi P, Dutta A. Social epidemiology of excess weight and central adiposity in older Indians: analysis of Study on global AGEing and adult health (SAGE). BMJ Open. 2015;5(11):e008608. doi:10.1136/bmiopen-2015-0086 $\underline{08}$

41. Finkelstein EA, Fiebelkorn IC, Wang G. National medical spending attributable to overweight and obesity: how much, and who's paying? Health Aff (Millwood). 2003;22(Suppl1):W3-219-W3-226. doi:1 0.1377/hlthaff.w3.219

42. Katzmarzyk PT, Janssen I. The economic costs associated with physical inactivity and obesity in Canada: an update. Can J Appl Physiol. 2004;29(1):90-115. doi:10.1139/h04-008 
43. Yach D, Stuckler D, Brownell KD. Epidemiologic and economic consequences of the global epidemics of obesity and diabetes. Nat Med. 2006;12(1):62-66. $\underline{\mathrm{d}}$ oi:10.1038/nm0106-62

44. Wang Y, Beydoun MA, Liang L, Caballero B, Kumanyika SK. Will all Americans become overweight or obese? Estimating the progression and cost of the US obesity epidemic. Obesity (Silver Spring). 2008;16(10):2323-2330. doi:10.1038/oby.2008.351

45. Wang YC, McPherson K, Marsh T, Gortmaker SL, Brown M. Health and economic burden of the projected obesity trends in the USA and the UK. Lancet. 2011;378(9793):815-825. doi:10.1016/s0140-6 736(11)60814-3
46. NCD Risk Factor Collaboration. Trends in adult body-mass index in 200 countries from 1975 to 2014: a pooled analysis of 1698 population-based measurement studies with 19.2 million participants. Lancet. 2016;387(1377-96):1377-196. doi:10.1016/S01 40-6736(16)30054-X27115820

47. Gill LE, Bartels SJ, Batsis JA. Weight management in older adults. Curr Obes Rep. 2015;4(3):379-388. do i:10.1007/s13679-015-0161-z

48. Chang VW, Alley DE, Dowd JB. Trends in the relationship of obesity and disability, 1988-2012. Am J Epidemiol. 2017;186(6):688-695. doi:10.1093/aje/kwX $\underline{092}$

49. Jacob ME, Yee LM, Diehr PH, et al. Can a healthy lifestyle compress the disabled period in older adults? J Am Geriatr Soc. 2016;64(10):1952-1961. doi:10.1111/ jgs. 14314 